Invited Editorial:

\title{
An Interview with Miriam Schcolnik: Reading, E- Reading and Writing and Their Assessment
}

\author{
Michael F. Shaughnessy \\ Eastern New Mexico University, USA
}

\begin{abstract}
Doi:10.19044/esj.2020.v16n28p1 URL:http://dx.doi.org/10.19044/esj.2020.v16n28p1
Submitted: 3 June 2020

Published: 31 October 2020

Copyright 2020 Shaughnessy M. Distributed under Creative Commons CC-BY 4.0 OPEN ACCESS
\end{abstract}

\begin{abstract}
Dr. Miriam Schcolnik (emerita) is the former Director of the Language Learning Center of the Division of Foreign Languages at Tel Aviv University. For three decades she coordinated and taught EAP (English for Academic Purposes) courses as well as a course in Technology in Language Teaching. She has developed many online learning environments, multimedia courseware packages, EFL textbooks, and teachers' resource books. Her research interests are e-reading and writing, and the use of digital tools to facilitate language learning and communication.
\end{abstract}

Keywords: Interview, e-reading

\section{Introduction}

Dr. Miriam Schcolnik (emerita) is the former Director of the Language Learning Center of the Division of Foreign Languages at Tel Aviv University. For three decades she coordinated and taught EAP (English for Academic Purposes) courses as well as a course in Technology in Language Teaching. She has developed many online learning environments, multimedia courseware packages, EFL textbooks, and teachers' resource books. Her research interests are e-reading and writing, and the use of digital tools to facilitate language learning and communication. 


\section{1) Dr. Schcolnik, first of all, what got you interested in foreign language learning, and then e-reading and writing?}

I love learning languages, so I guess becoming interested in language learning was a natural consequence. I started teaching English as a Foreign Language in 1965, in Montevideo, Uruguay. At the time, the prevalent method for language teaching was still the Audiolingual Method, based on behaviorism. The belief was that through drill and practice language patterns would become automatic. Over the years, linguists and language professionals revised the concept of what it means to learn a foreign language, and the emphasis switched from habit formation to awareness and comprehension. I didn't know at the time that a few years later I would become involved with machines and computer-assisted language teaching! But when I started working at Tel Aviv University, the head of my department (The Division of Foreign Languages) was the late Dr. Roberta Stock, who had been involved in the development of the first Computer Assisted Instruction modules in English in the Control Data PLATO project at the University of Illinois (See Hart, 1981, and timeline at https://chip.web.ischool.illinois.edu/people/projects/timeline/1960won.html Roberta received a donation to buy a few Control Data microcomputers and courseware and introduced CAI (Computer Assisted Language Instruction) in the department. She asked for volunteers to learn the system and implement it in the pre-academic English courses and taught us about the potential of the technology. I was hooked from the start.

The idea that technology could help people learn languages was exciting, and thanks to Roberta in the summer of 1983 I got involved in the CAI Project at Tel Aviv University. My MA thesis was an evaluation of the project and of the English reading skills courseware we were using at the time. The assumption underlying the introduction of computers in the courses was that CAI could positively affect the learning of reading comprehension strategies in English as it provided intensive individual practice, allowing students to work at their own pace.

Roberta believed computer technology could facilitate language learning in general, and as the technology improved, she became one of the most salient proponents of CALL (Computer Assisted Language Learning) in Israel. In 1993 she founded a multimedia company (Q Multimedia) that developed programs for learning languages. She invited me to join the courseware development team, and I gladly did.

For many years, the emphasis in our EAP (English for Academic Purposes) courses was on reading comprehension. Most of our students are speakers of Hebrew or Arabic and despite the emphasis on English in the school system, long academic texts in English can still be an obstacle. In the lower-level courses, we taught reading skills and strategies using shorter 
texts, whereas in advanced English courses students already dealt with authentic academic texts relevant to their majors (such as Physiotherapy, Computer Science, Political Science, and Engineering).

We were excited by the possibilities afforded by the technology, and as soon as our department got standalone PCs, we started to develop our own courseware to better suit our students' needs. Students could work at their own pace, get feedback on their answers, look up words in the built-in glossary, clarify what a certain grammatical structure meant, and listen to the written texts, among other things. Several years later, with the advent of the Internet at our university, we were able to discontinue the use of closed courseware and develop more open-ended tasks based on online texts and taking advantage of the numerous tools available online, such as monolingual and bilingual dictionaries, thesauri, concordances, and resources such as encyclopedias and online libraries where students could explore a topic and, with the additional background information, expand their comprehension of the text.

When the first dedicated e-book devices, such as the Rocket Ebook (https://en.wikipedia.org/wiki/Rocket_eBook), appeared in 1998, I decided to do my doctoral dissertation (Schcolnik, 2001) on reading with dedicated ereaders. Researchers predicted that in the future our reading would be mainly digital, as digital texts were convenient, searchable, affordable, environment friendly, could be used anytime and anywhere, and had storage advantages over print. I wanted to understand what this emerging technology was suitable for and whether it was suitable for different purposes of reading, such as reading for information or reading for pleasure. I also wanted to see what features e-texts should have and what strategies users applied to ereading. One of the issues that I thought would need to be researched in the future was the effect of e-readers on attention while reading.

As director of the Multimedia Language Learning Center, I also became involved in research on academic writing, which was at first only taught in courses for Ph.D. students and included in EAP courses at all levels in the last few years. I am mainly interested in the new possibilities offered by the technology, how the process of writing has changed, and the many tools available for writers (Schcolnik, 2018) writing in both their first and second languages.

\section{2) In your mind, how does e-reading differ from traditional reading a hardback or paperback book?}

A new technology or medium does not just add to the way we do things, it changes everything (Postman, 1998). So, what does reading on screen do to the way we read? What does the Internet do to the way we read? In the last two decades, a lot of research has focused on the various aspects 
of e-reading and how it differs from reading from print. Researchers from different fields are researching e-reading: library science is interested in what e-reading is used for and how, and libraries need to have a policy for acquisition, lending platforms and copyright issues; educational technology and human-computer interaction experts look at usability, interface design, and actual use; reading experts look at reading strategies and the effect of the medium on reading; device manufacturers look at ways to improve the devices, and book publishers want to find out consumer preferences to develop suitable marketing strategies.

The new literacies involved in online reading include knowing how to sift through many sources of information to find the most suitable ones, with persistence, flexibility, confidence, and skepticism (Coiro, 2009). However, not all e-reading is on the Internet. We must differentiate e-reading on a dedicated device from online reading. E-readers are designed using the book metaphor rather than the computer metaphor. The kind of literacy needed for reading on e-readers is probably close to the traditional reading literacy required for reading a printed book (Schcolnik, 2002). I have seen many cases of adults whose computer literacy is minimal and yet happily adopt e-book readers for leisure reading.

Some differences between reading from screens and reading from print have to do with the nature and characteristics of the text or the interface, while others are connected with the readers' approach to the text. Just to name a few, there are differences related to the direction in which we read (e.g., linearly or hypertextually), the depth of reading (e.g., word spotting or reading to analyze, reflect and learn), reading speed, reading strategies (e.g., skimming, highlighting), text navigation (scrolling or paging), text display (e.g., one page at a time or whole text on one long page), tools available (e.g., printed glossary or digital dictionary), user concentration, and reading interfaces and affordances (e.g., small screen, such as Kindle, smartphone or tablet, large screen, A4 printed page). Let's look at some of the differences in more detail.

\section{Direction: Linear or hypertextual}

According to Nielsen (2008), most people arriving at a website know what they want and pursue their interest in a non-linear fashion. The World Wide Web is a hypermedia system that allows users to navigate in all directions by following links. On the one hand, the system allows for a lot of flexibility, as users do not need to follow a prescribed linear path. On the other hand, this feature could result in a lack of focus and disorientation. We can teach certain strategies for staying on track, such as keeping the main purpose of the reading in mind. Dealing with non-linear text implies the ability to go back to the original point of origin. 


\section{Text presentation and navigation}

Digital texts come in a variety of formats. Some, for example, are offered as .pdf files and look just like their printed counterparts, including page numbers, tables, and illustrations. We can go through these texts by either paging down or scrolling. Others may be HTML files or word processor documents that require scrolling. Digital text presentation is an important factor affecting reading and reading comprehension, and in educational settings, where reading is mainly for learning, a variety of formats should be made available (Schcolnik \& Kol, 2005, 2006).

Baker (2003) examined the use of paging vs. scrolling and their effect on reading. He found reading time in the paging condition to be significantly slower than in the scrolling condition. However, the performance was not significantly different. Scrolling is commonly used when skimming web pages (Nielsen, 1997). As a result, people now have more experience with this navigation method.

What method of navigation produces better results when 'reading to learn'? In a study to investigate the effect of text presentation on learning (Schcolnik \& Kol, 2006), we found that students who learned from continuous (HTML) text performed significantly better than students who learned from a reader -- where the amount of text on a page was limited. Also, most students expressed a preference for scrolling.

\section{How we read}

Browsing, skimming, and scanning seem to be the prevailing strategies used to deal with texts on the Internet. Over a decade ago, Liu's (2005) study showed that people spent more time browsing, scanning, and one-time reading, and less time deep reading. Over half of the subjects reported never annotating or highlighting electronic documents, whereas most said they did annotate printed documents.

More recently, the Nielsen team (Pernice, Whitenton \& Nielsen, 2011) conducted a study in which they used eye-tracking technology to document how users interact with websites. They identified patterns in the way people moved their eyes when reading on the web. Based on the observation of over three hundred people, they found that people mostly scan rather than read. When confronted with a large block of text, most people scan in an F-shaped pattern. Sentences that appear in the middle or towards the end of the text may go unnoticed.

I experienced this myself a few weeks ago when ordering groceries online (being a "digital immigrant", I normally prefer shopping at the supermarket). When I went into the supermarket website, the first thing I saw was a popup explaining that due to the Corona crisis there may be delays in deliveries. I did not read to the end and supposed they were just apologizing 
for delays. I quickly closed the popup to get on with my task of ordering the groceries. When I was through, the site offered a list of possible delivery dates. Only a few dates were visible, and when hovering over them they all displayed the message, "Deliveries not available on this date". I was very upset and just left the site. However, a couple of hours later, I decided to try again (I did need the groceries, after all!). Thankfully, my order was still there, and this time I read the entire popup. It said that users should refresh the page where a choice of dates was offered, as available dates were updated every few minutes. Displaying typical online reading behavior, I had had little patience to read the message on the popup to the end!

"The act of scanning is like a treasure hunt, where each word fixated on is another place where the explorer looks for the treasure" (Pernice et al, 2011, p. 14). When scanning on paper, our eyes move quickly over the text looking for specific information. When scanning digital text, readers can search for specific information by using the Find feature (Kol \& Schcolnik, 2000). In our book (Schcolnik \& Feuerstein, 2018) we suggested many activities that instructors can implement to practice scanning different types of text (e.g., lists, timelines, tables, or articles) on paper and on screen.

In the late nineties, my colleague Sara Kol and I were already concerned with the differences between print and screen reading because we saw that more textbook material was offered online, and in addition to the difficulty of reading in English, our students would be confronted with a new medium. In our first study (Kol \& Schcolnik, 1997) we found that advanced EAP students who were not experienced computer readers could neither scan nor skim texts effectively on screen. We subsequently taught students screen reading strategies and found that after instruction they were able to scan better from a screen than from paper and also skim and close read as well as on paper (Kol \& Schcolnik, 2000).

Things have changed a lot since then. Gen $\mathrm{Z}$ students have grown up surrounded by screens and using them to read is second nature to them. According to Wolf (2018), skimming is the new normal. She claims that we have changed as readers. We skip a lot of material because we don't want to spend the time, and therefore we do not process or analyze what's in the text.

Moran (2020) summarizes the Nielsen Group's findings reported in the $2^{\text {nd }}$ edition of their report How People Read Online: The Eyetracking Evidence (https://www.nngroup.com/reports/how-people-read-webeyetracking-evidence/), which come from a series of studies extending over 13 years, with 500 participants and more than 750 hours of eye-tracking time. They found that online scanning behavior hasn't changed, and the main strategy on the web is still scanning rather than reading. Interestingly, they found very similar reading patterns across languages, including languages like Chinese and Arabic. 
When we look at reading strategies, we must differentiate them according to reading purpose, i.e, reading for information, or reading for pleasure. When we read for information, we search, skim, scan, and close read. When reading for pleasure (such as on Kindle), we use strategies that are similar to those we use when reading a printed book: we mainly page forward, and occasionally backward to double-check something.

Salmeron \& Llorens (2019) researched a new type of instruction of ereading strategies combining eye-movement examples and videos to teach ninth-grade students to plan, monitor, and evaluate their digital reading. Students saw eye movement examples and heard an audio recording of a high school student verbalizing what she was thinking while doing the task. Then they discussed what they had seen and heard. Their results showed that this type of training can be effective for teaching students to monitor and evaluate their digital reading.

\section{Attention, concentration, and depth of reading}

When reading online, there are many distractions. Baron (2017) conducted a series of surveys of over 400 university students aged 18-26 in five different countries. Among other questions, she asked them how likely they were to multitask while reading, and in which medium they felt they concentrated best. Students reported they were more likely to multitask when reading on screen. Regarding concentration, $92 \%$ said it was easier to concentrate when reading print.

In his book, The Shallows (2011), Carr claims that the Internet has a negative effect on the way we read. On the Internet, concentration and depth of reading decrease. We browse and scan to gather information but do not stop to reflect on that information. This was also demonstrated in Liu's study (2005), where participants said they spent less time reading in-depth and had trouble concentrating due to online distractions such as pop-ups.

Deep reading is "the array of sophisticated processes that propel comprehension and that include inferential and deductive reasoning, analogical skills, critical analysis, reflection, and insight" (Wolf and Barzillai, 2009, p. 32). Wolf (2018) laments the fact that we rarely deep read and relates an experience she had when trying to read a print book she had read and enjoyed several times in the past but now had trouble getting through. Baron (2017) says that we are used to using digital platforms for quick action, such as skimming newspaper headlines or looking up an address. She wonders whether the meaning of reading is changing to finding information instead of contemplating and understanding.

I think many of us now feel that we have less patience to embark on a deep reading of long documents. Aware of this fact, many print newspapers 
have started to highlight important passages in long articles to cater to this new style of reading.

\section{Comprehension}

In a study looking at the effects of reading on screen in a Norwegian school context (Mangen, Walgermo \& Bronnick, 2013), students who read in print scored significantly better on the reading comprehension test than students who read the pdf texts digitally. This was true for both narrative and expository texts.

Clinton (2019) conducted a review and meta-analysis of the research -- a total of 29 reports between 2008 and 2018 -- on reading from screens as compared to paper focusing on reading performance, reading times, and metacognition. Reading from screens had a small negative effect on reading performance compared to paper. There were no differences between the two media for reading time. Readers also had a more accurate judgment of their performance from paper compared to screens.

In an experiment dealing with literary reading and comparing Kindle and a print book (Mangen, Olivier \&Velay, 2019), results showed that subjects using the Kindle had more trouble localizing events temporally in the story. There was no difference in reading time, estimated number of pages, reading comprehension, and narrative engagement, but print readers had better recall of temporal relations between events and better reconstruction of the plot. In both media, page numbers were available, and yet the print readers did better.

A meta-analysis (Delgado et al, 2018) examining recent research comparing the reading of texts on paper and digital devices revealed an advantage of paper over digital reading when reading informational or mixed genres, but not so in narrative texts. The advantage increased in timeconstrained reading compared to self-paced reading. It also increased over time.

Ackerman \& Lauterman (2012) stress that the finding of screen inferiority under time pressure is especially relevant for computerized tests, such as the TOEFL, which is administered via the Internet. Policymakers should take into account possible bias in the results due to the medium.

\section{Preferences: Print or screen?}

In Liu's study (2005) $80 \%$ of participants reported always or frequently printing out electronic documents for reading, and $90 \%$ said they preferred paper as a reading medium. This was also the finding in a larger and much more recent study. In an international survey (Mizrachi, Salaz, Kurbanoglu \& Boustany, 2018) of academic reading format preferences of over ten thousand tertiary students carried out in 21 countries from 2014 to 
2016, Mizrachi et al found that the majority of students (78.44\%) prefer to read academic course materials in print. They reported that with print materials they could focus better and their retention was better. They were also more likely to reread, highlight, and annotate printed materials. Preference for print was consistent worldwide. For most of the students, the language of the text did not influence their preferences. Dennis (2011), on the other hand, strongly believes that paper textbooks will be replaced by etextbooks. System logs at the University of Indiana showed that $68 \%$ of students did not print a single page. In the survey, most students (87\%) reported reading the e-textbook rather than the printed textbook.

COST (European Cooperation in Science and Technology) E-READ (Evolution of reading in the age of digitization) aims to improve our understanding of the influence of digitization on reading practices and to find ways to take advantage of both "paper and digital technologies across age groups and purposes" (Stavanger Declaration, p. 1). The team of 200 scholars from across Europe focused mainly on comprehension and retention when using print versus digital materials and made a series of recommendations for both research and practice. They stress the importance of the cooperation of educators, reading experts, psychologists, and technologists.

\section{Implications for education}

What are the implications of all this research for education? Our students are either millennials or Gen Z (Dimock, 2019), or using Prensky's term, "digital natives" who think and process information differently from older generations (Prensky, 2001, Part 1, p. 2). They are "native speakers" of the digital language. I believe that just as native speakers of a language need to learn how to listen and read with comprehension and how to communicate effectively orally and in writing in their first language, so do digital natives, and educators should teach them sound, effective e-reading strategies. They grew up surrounded by technology, and yet, educators need to make sure they learn effective digital literacy skills, as well as print literacy skills (Schcolnik \& Feuerstein, 2018).

I believe that for students to become good readers of digital text, besides being aware of the options and tools available, and being competent in navigating and interacting with the digital text, they need to know how to select reliable content and how to apply effective reading strategies to process the text. Teaching digital natives reflection and critical thinking is an interesting challenge (Prensky, 2001, Part 2). Even though recent research shows the inferiority of screens as compared to paper concerning reading comprehension, digital reading is now an integral part of most educational 
systems, and it is therefore important to help students develop effective digital reading strategies (Delgado, Vargas, Ackerman \& Salmeron, 2018).

\section{How do you go about assessing and evaluating a student's reading rate, reading comprehension on an e-book, or is it even necessary?}

Even though reading rate is closely related to reading fluency and can therefore influence reading comprehension, I do not usually assess reading rate. It is true that indirectly, a slow reading rate could be problematic, both in test situations, where there is a time limit and in real life, where most people have limited time! However, reading rate should not be any different on screen and on paper. Factors such as word recognition affect rate in both media.

English language students may struggle with word recognition in English well after they have achieved a good reading rate in L1, because good reading does not automatically transfer into second language reading unless native-language proficiency has been reached. For students whose L1 uses the same alphabetic system as English, reaching a suitable reading rate in English will be less difficult than for those whose L1 uses a different system, provided they have learned English sound-letter correspondences and have enough vocabulary knowledge to deal with the text.

As for reading comprehension, comprehension should be assessed in both media. Most reading comprehension tests (regardless of medium) include global questions, tapping, for example, text organization, the purpose of the text, main ideas, sequence of events, and conclusions. Also, they include questions that deal with local information such as facts, generalizations, and examples.

The strategies used to arrive at the answers will be different for digital text, and we need to make sure that our students know how to go about using them. For example, in our book (Schcolnik \& Feuerstein, 2018), when dealing with finding information in texts, we devote separate sections for paper and screen strategies and encourage teachers to explicitly teach the strategies.

Reading on the Internet, however, is not merely reading from a screen. It is a different type of reading, and therefore, instructors need to make sure that assessment tasks are suitable for online reading. According to Coiro (2009), online reading comprehension assessment should take into account how the concept of literacy is changing. A typical Internet-based reading assignment "requires students to generate appropriate search requests, sift through disparate sources to locate their own texts, synthesize the most reliable and relevant information within those texts, and respond with online communication tools such as an e-mail message or blog post" (p. 59). 


\section{4) Do you ever ask a student or learner to read parts of an e-book aloud to you to assess fluency?}

Grabe (2009) raises the question of whether L2 students can read with comprehension even when reading slowly, and explains that in academic settings, fluency can help students deal with the long texts they are assigned. He defines fluency in reading as "the ability to read rapidly with ease and accuracy and to read with appropriate expression and phrasing" (p. 291).

There are many arguments against reading aloud in L2 classrooms, such as the fact it's boring and anxiety-provoking, it interferes rather than facilitates comprehension, it is not a skill that many people need, and it could be demotivating for students. But there are also possible benefits, such as the fact it can help students make connections between sounds and letters, develop fluency, improve pronunciation and intonation, and it can be used as a diagnostic tool (Gibson, 2008).

Some students are more willing than others to read aloud in class. Many are embarrassed to 'perform' in front of their classmates. Therefore, I encourage students to practice reading aloud at home and sometimes ask them to record their voices, so I can assess pronunciation and fluency. This gives students a chance to practice a passage several times before recording their voices. The technique constitutes a learning opportunity as well as an assessment task. Repeated reading has been shown to have positive effects on both fluency and comprehension (Grabe, 2009), and this can be done by students at home. Depending on the level of the course, a recorded model could be provided.

\section{5) Are there any specific reading tests that you employ with your various students?}

In institutions of higher education in Israel, students who do not get exempted from English courses in the psychometric exam (the higher education entrance exam) need to take one or more EAP courses, depending on their level. The final exam in the exit-level course presents students with a set of questions on an authentic academic text. The questions demand comprehension of the main points made by the author and evaluation of the coherence and validity of the arguments presented as support. But in the courses, many alternative methods of assessment are used concurrently with traditional tests. These include portfolios, oral reports, group projects, individual written reports, peer assessment, self-assessment, pair quizzing, outlines, and the preparation of handouts for an oral report.

Several years ago I gave a presentation at the University Teachers of English Language in Israel (UTELI 2009) conference titled Breaking Down the "One-Size-Fits-All" Barrier in Language Assessment. I 
suggested students should be offered assessment choices; for example, the choice of whether to read the text on screen or on paper during tests. However, I also stressed the importance of using other forms of evaluation besides tests. Courses should include task-based assessment, where students demonstrate their language knowledge by creating webpages, blogs, podcasts, or digital stories, giving oral presentations, and making flowcharts or graphics to represent what they have read.

It is true that there are problems with task-based or alternative language assessment, such as consistency, generalizability, and reliability. However, if this type of assessment is combined with more traditional measures, the final grade should be representative of the students' work and achievements.

An example of alternative assessment that I used in my Advanced EAP courses for engineering students was the option to do a final webpage development project for the course. Those who chose to do the project (instead of another task) received guidelines for webpage development (DOs and DON'Ts and a list of required and optional components) as well as a checklist of the assessment criteria I would use to assess their work. They were encouraged to use the criteria to evaluate their project before submitting it.

One of the required components of the webpage was a podcast or recording of the students' voices, in which they could summarize important information on the subject they researched, discuss their own views, etc. The recording was worth $30 \%$ of the grade, broken down into three components, clarity, fluency, and use of relevant vocabulary. The rest of the webpage was worth $70 \%$, including credit for the organization, introduction, conclusion, language, bibliography, suitability of sources, reliability of the information, format, and esthetics. When asked why they had chosen to do the webpage project, several reasons were given, such as "thought it would be fun", "wanted to learn how to do a webpage", "like new challenges", but over $60 \%$ of the students said for them it was easier to do things on the computer than in front of the class.

Webpage publishing is yet another example of an assessment option that also provides a learning opportunity. To create the webpage students had to research a topic, synthesize the information, organize it, find visuals to accompany the text, record their narration, and finally publish their pages. While doing the final project they learned both language skills and web literacy skills. The motivation was high. The task involved critical reading, synthesis of various sources, writing, speaking, in other words, purposeful language use.

Most texts in our courses are now offered online, and some students prefer reading on screen, so the option of tests on the screen should be 
offered. Obviously, in large-scale standardized tests, it is more difficult to offer options. However, this is sometimes done. For example, in Israel, NITE (National Institute for Testing and Evaluation) is responsible for the psychometric test (See https://www.nite.org.il/psychometric-entrancetest/about-the-test/?lang=en), which is the entrance test for all higher education institutions in the country. Students can also take the English section separately. The English test assesses English language proficiency and there is a computerized version of the test as well. Students can choose whether to take the regular version or the computer version. The grade is then used by academic institutions for placement purposes.

\section{6) You have developed some online learning environments- What are your} concerns about student's ability to read what is on those learning management systems and their ability to navigate around them?

Reading what is on the systems is, for the most part, a matter of good web typography. Material input by the instructor, such as tutorials, guidelines for tasks, lists of resources, and others should have fonts that are consistent and large enough. Reading materials that come from other sources, however, may be pdf files, doc, HTML, or ppt files, and reading them will imply the issues I discussed in question 2. In general, our students manage well reading the materials on the course OLEs (online learning environments).

Regarding navigation, I am concerned about how the content is organized (or not) in these environments. Most learning management systems offer good options that can be exploited by the developer (usually the instructor). such as tools for collaboration, assessment, and content presentation, but not all developers develop organized environments.

Rich OLEs provide opportunities for searching for information and meaningful interaction and cooperation, course materials, suggested sources of additional materials and tools, and assessment components. They should be organized to avoid disorientation and should be a friendly environment where students can navigate the materials without encountering barriers and difficulties. Students should always know where things are and how to find them. Northcote (2008) suggests the OLE could include advice on how students can "negotiate their way through the maze of information, activities, and resources" (p. 681), such as sitemaps or tips.

When the instructional objectives are made clear, grasping the organization of the OLE should not be an arduous task! To avoid the disorientation that can occur on the Internet when following hyperlinks and not knowing how to get back to the source, the OLE should provide a HOME for the user to return to. 


\section{7) How do you decide at what grade level an EFL textbook should be written?}

Usually, the decision of what level a book should be is determined by perceived need. For example, when a new curriculum for the schools is published by the Ministry of Education. The official curriculum is prepared by a curriculum subcommittee of the ministry, consisting of the Chief Inspector for English Language Education and academic counselors and consultants from different universities and colleges. The new curriculum is always based on current research in second language learning and specifies the language skills students are required to develop in English at each level of study. The approach and recommendations of the curriculum need to be reflected in the textbooks.

Therefore, when a new curriculum is published, textbook writers develop new textbooks for various levels. Every new textbook for the school system requires approval by the Ministry of Education before it can be used in the schools. It is often the case that writers decide on a series of textbooks (rather than single books) for several levels (for example, junior high). The series is then designed with a common philosophy or approach to language learning. All books in the series thereby share general goals, skills, and organization. However, each book in the series incorporates the specific skills, functions, structures, and vocabulary recommended for the grade level it is intended for.

\section{8) What digital tools are out there to help students who have reading problems?}

Many new tools can help students with reading problems. There are different kinds of reading problems, but I'll focus here on dyslexia, which is the type we most frequently encounter in my department. Dyslexics have problems reading in a foreign language, especially if the foreign language uses a different sound-symbol system. At the college level, the demands for rapid and efficient reading comprehension skills put LD (learning disability) students at high risk for failure in foreign language classes, due to their phonological processing deficits (Downey, Snyder \& Hill, 2000).

In Israel, by the time students get to university, they have studied 8 or 9 years of English in school and may have a good command of listening and speaking skills as well as a fair command of reading. However, while most content courses are conducted in Hebrew, most reading requirements are in English. Students need to be able to read well in English so they can succeed in their specific academic disciplines. Coping with long academic texts in English is particularly challenging for LD students.

Allow me a bit of history here: In the late nineteen eighties, my colleague, the late Yedida Heymans, took it upon herself to find ways of 
helping dyslexic students who needed to take English courses in our department. At the time, there were fewer technologies available, articles used in courses were read on paper, and the texts for reading comprehension tests were on paper as well.

The first commercial reading machine for the blind was developed by Kurzweil Computer Products in 1975 (https://en.wikipedia.org/wiki/Reading_machine). Reading machines could scan text and using optical character recognition and speech synthesis could read the text out loud. Tel Aviv University had several machines available in libraries that could also be used by LD students, but Yedida knew that we needed to offer access to TTS (text to speech) to more students than was possible in the library.

Yedida was always looking for ways of helping LD students. Before they even started their English courses, she would interview every student that had officially been diagnosed as dyslexic by the office of the Dean of Students. She had prepared a set of enlarged texts on different color paper and she would check which background color the student felt most comfortable with. She then informed the course instructor of the results, and that was the color of the paper on which that student's tests were especially printed and enlarged.

In addition, she obtained a budget to buy TTS software, which could be used by the students in our Learning Center for reading assignments and tests. While other students read and answered test questions on paper, LD students had a special time slot in the Learning Center where they could use the TTS software while reading the texts on the computer screen. She also recruited English-speaking volunteers who would record all the texts required for each of the various level courses. Dyslexic students could then borrow the tapes for the semester to help them when reading long articles for homework. Years later online TTS programs started to be available, and nowadays text-to-speech technology is used widely in educational settings (Wood, Moxley, Tighe \& Wagner, 2018).

A colleague recounted the following anecdote some years ago: One of her dyslexic students was getting very low grades on tests, but as soon as she suggested that he come to the Learning Center and use the TTS program daily, and of course also for tests, the student started getting much higher grades. Now, of course, students can use TTS programs on their laptops or phones, as TTS programs are available online. For example, Read Aloud is a TTS Chrome and Firefox extension that converts webpage text to audio. It offers a wide variety of languages, voices, and speeds. Another example is TTSReader (ttsreader.com). It is also important to note that the quality of TTS has improved greatly in the last few years. 
Regarding the physical characteristic of text, it is no longer necessary to print enlarged texts on different color papers. Most digital text displays can be customized. By changing the text size, color, and background, font, line spacing, and word spacing, readers with difficulties can obtain much more readable text.

The results of a study to measure the effect of different background colors on-screen readability (Rello \& Bigham, 2017) showed that background colors have a significant impact on readability. Warm background colors significantly improved both reading performance and reading time. The researchers pointed out that people with dyslexia may especially benefit from the use of suitable background colors.

9) What are the assessment/evaluation issues in e-reading-particularly if you have instructors who only use e-books and PDFs?

In courses in which instructors only employ digital texts, tests and other types of assessment should be on computers as well, to ensure validity. However, certain practical problems can impact the decision to do the test using computers. If the test is administered in a computer lab, then the Internet must be disconnected to avoid cheating. If the test is done on the students' laptops, it is more difficult to achieve such a neutral environment. How can instructors make sure students are not communicating with others during the test? Or using resources they were not supposed to access?

On the other hand, if all texts are read on-screen and the exam is administered on paper, the medium is likely to bias and invalidate the results. As discussed in question 2, the strategies used for reading from a screen and paper are different, so how can we expect students who are used to activating reading strategies on screen deal with printed texts on tests?

In an ideal world, tests should tap critical thinking, the ability to synthesize information, views, or arguments from different sources, reflect, solve problems, evaluate, and apply the knowledge acquired. Perhaps this kind of test can be administered on computers regardless of the risks mentioned above, simply because students do not need to regurgitate "the right answers" but rather are expected to provide their answers and sufficient support.

10) A global question: How has PowerPoint changed reading and the reading process? It seems that many students eschew the text and hope to survive a course just by reviewing PowerPoints.

I don't think PowerPoint has changed the reading process, but perhaps what you are asking about is related to how we all now read, with less patience or willingness to read in-depth (as I discussed in question 2). I don't have any personal experience with that, since language teaching is 
normally interactive, and the "PowerPoint syndrome" applies mainly to lecture courses. I have some ideas, though, as to how to possibly cure this affliction.

In a study that investigated the effect of PowerPoint on content learning (Pros, Tarrida, Martin \& Amores, 2013), the researchers compared content delivered in two modes, one with PowerPoint and the other with the aid of the blackboard. Students were assessed immediately after the lecture. The results showed significantly higher scores for the blackboard condition. This is not necessarily related to your question about reading but may be due to the students' passivity while following PowerPoint bullets in a lecture.

There have been studies dealing with the provision of PowerPoint slides and how this affects attendance and performance (e.g., Worthington \& Levasseur, 2015), and studies looking at whether it is better to provide partial or full notes (e.g., Cornelius, 2008, cited in Worthington \& Levasseur, 2015). In one class the PowerPoint slides had complete lecture notes, and in the other, the slides only included limited information such as headlines or definitions. Their results showed that students who were given partial notes performed better.

Interestingly, in the MA program in philosophy and business at the Copenhagen Business School, the use of PowerPoint in lectures was banned, although lecturers are allowed to use PowerPoint slides for images, videos, or important quotes (Sorensen, 2015).

Lectures transmit information and do not necessarily encourage reflection, participation, or expansion. It's the "sage on the stage" model aided by technology rather than the "guide on the side" model. So, what can we do about this? Perhaps when the slides contain ALL the information, they become a form of spoon-feeding. As shown in the study by Cornelius (2008), it seems best not to have full-blown notes on the slides. The slides can have pointers, illustrations, provocative questions, problems, or dilemmas. I believe we need to make sure students participate actively in the lesson. The presentation can act as the stimulus or trigger to start a discussion based on the readings that were assigned beforehand. If this is the model adopted, the slides can be provided before the lecture and students would have no choice but to read the literature, to come to class prepared to answer the questions.

I think there is no need to ban PowerPoint, but it should be used differently --so students will not be able to take the PowerPoint shortcut and avoid reading the source texts.

\section{1) What have I neglected to ask?}

You did not ask about the use of audiobooks or podcasts for learning. I have been an audiobook fan since 2002, and I listen for pleasure whenever 
I have a chance, mainly while driving. However, I am also intrigued by the potential of using audio -- not just audiobooks, but also podcasts and online talks -- in education. Not only have audiobooks become widely accepted in education, but they are also an integral part of many library collections (Moyer, 2012).

A study (Daniel and Woody, 2010) comparing the retention of students listening to podcasts to that of students reading the text showed that performance was better for the reading group. The researchers suggest that podcasts could be a good supplement to content delivered in texts. Another study (Rogowsky, Calhoun \& Tallal, 2016), however, yielded quite different results. The study investigated the effect of input mode -- e-text, audio, or both simultaneously -- on comprehension and 2-week retention of a nonfiction book. The subjects were native English-speaking college graduates. The results showed no statistically significant differences among the comprehension and retention scores in the three modes. The authors suggest that the difference from the results in the Daniel \& Woody study may be due to the fact that in the Daniel \& Woody study participants were allowed to review the content before taking the test, and it may have proven harder to review the content in the podcast condition.

In the tertiary education context, audio podcasts can bring to students the voices of experts in a variety of fields, and provide new learning and reviewing opportunities, and enhanced note-taking skills, among other benefits. I believe there is no reason to substitute written texts with audio, but audio files, which can be available anywhere and anytime can constitute a great supplement to a course. In the case of EAP courses, podcasts can be used as assistive technology to help LD students, and also as regular features accompanied by listening comprehension questions or tasks. They can also allow for exposure to a variety of English accents, thus broadening the students' ability to understand more than one variety of spoken English. 


\section{References}

1. Ackerman, R. \& Lauterman, T. (2012). Taking Reading Comprehension Exams on Screen or On Paper? A Metacognitive Analysis of Learning Texts Under Time Pressure. Computers in Human Behavior, 28, 1816-1828. Elsevier.

2. Baker, J.R. (2003). The Impact of Paging vs. Scrolling on Reading Online Text Passages. Usability News, February 2003, 5(1).

3. Baron, N. S. (2017). Reading in a Digital Age. Phi Delta Kappan, 99(2), 15-20. Available: https://kappanonline.org/reading-digitalage/.

4. Carr, N. (2011). The Shallows: What the Internet is Doing to Our Brains. New York, London: W. W. Norton \& Company.

5. Clinton, V. (2019). Reading from paper compared to screens: A systematic review and meta-analysis. Journal of Research in Reading, 42(2), 288-325.

6. Coiro, J. (2009). Rethinking Online Reading Assessment. Educational Leadership 66(6), 59-63.

7. Cornelius, T. L., \& Owen-DeSchryver, J. (2008). Differential effects of full and partial notes on learning outcomes and attendance. Teaching of Psychology, 35, 6-12.

8. COST E-READ (2018). Stavanger Declaration Concerning the Future of Reading. Available: https://ereadcost.eu/stavangerdeclaration/

9. Daniel, D.B. \& Woody, W.D. (2010). They Hear, But Do Not Listen: Retention for Podcasted Material in a Classroom Context. Teaching of Psychology, 37, 199-203.

10. Delgado, P., Vargas, C. Ackerman, R. \& Salmeron, L. (2018). Don't Throw Away Your Printed Books: A Meta-Analysis on the Effects of Reading Media on Reading Comprehension. Educational Research Review, 25, 23-38.

11. Dennis, A. (2011). e-Textbooks at Indiana University: A Summary of Two Years of Research. Available: https://assets.uits.iu.edu/pdf/eText\%20Pilot\%20Data\%2020102011.pdf

12. Dimock, M. (2019). Defining generations: Where Millennials end and Generation $\mathrm{Z}$ begins. Fact Tank, Pew Research Center. Available: https://www.pewresearch.org/fact-tank/2019/01/17/wheremillennials-end-and-generation-z-begins/

13. Downey, D.M., Snyder, L.E. \& Hill, B. (2000). College Students with Dyslexia: Persistent Linguistic Deficits and Foreign Language Learning. DYSLEXIA, 6, 101-111. 
14. Gibson, S. (2008). Reading aloud: a useful learning tool? ELT Journal, 62(1), 29-36, January 2008. Oxford University Press.

15. Grabe, W. (2009). Reading in a Second Language: Moving from Theory to Practice. The Cambridge Applied Linguistics Series. Cambridge University Press.

16. Hart, R. (1981). Language Study and the PLATO System. Studies in Language Learning, 3(1). Abstract available at https://eric.ed.gov/?id=ED218931

17. Kol, S. \& Schcolnik, M. (Fall 1997). Reading from Screen vs. Reading from Paper: A Pilot Study. CAELL Journal, 8, 1, 10-14.

18. Kol, S. \& Schcolnik, M. (June 1997). Reading on Screen Vs Reading on Paper: Can the Same Strategies Be Applied? Proceedings of the CALICO 1997 Annual Symposium: Content, Content, Content.

19. Kol, S. \& Schcolnik, M. (2000). Enhancing Screen Reading Strategies. Calico Journal, 18, 1, 67-80.

20. Liu, Z. (2005). Reading behavior in the digital environment: Changes in reading behavior over the past ten years. Journal of Documentation, 61(6), 700-712.

21. Mangen, A., Walgermo, B.R. \& Bronnick, K. (2013). Reading linear texts on paper versus computer screen: Effects on reading comprehension. International Journal of Educational Research, 58, 61-68.

22. Mangen, A., Olivier, G. \&Velay, J.L. (2019). Comparing Comprehension of a Long Text Read in Print Book and on Kindle: Where in the Text and When in the Story? Frontiers in Psychology, $10: 38$.

23. Mizrachi, D., Salaz, A. M., Kurbanoglu, S., \& Boustany, J. (2018). Academic reading format preferences and behaviors among university students worldwide: a comparative survey analysis. PLoS ONE 13(5):e0197444. Available: https://journals.plos.org/plosone/article?id=10.1371/journal.pone.019 7444

24. Moran, K. (2020). How People Read Online: New and Old Findings. Nielsen Norman Group. Available: https://www.nngroup.com/articles/how-people-read-online/

25. Moyer, J.E. (2012). Audiobooks and E-books: A Literature Review. Reference \& User Services Quarterly, 51(4), 340-354.

26. Nielsen, J. (1997). Changes in Web Usability Since 1994. Available: https://www.nngroup.com/articles/changes-in-web-usability-since1994/.

27. Nielsen, J. (2008). Writing Style for Print vs. Web. Available: http://www.useit.com/alertbox/print-vs-online-content.html. 
28. Northcote, M. (2008). Sense of place in online learning environments. In Hello! Where

29. are you in the landscape of educational technology? Proceedings ascilite Melbourne 2008, 676-684. Available: https://www.ascilite.org/conferences/melbourne08/procs/northcote.pd $\mathrm{f}$

30. Pernice, K., Whitenton, K. \& Nielsen, J. (2011). How People Read on the Web, The Eyetracking Evidence. Nielsen Norman Group. Report available: https://www.nngroup.com/reports/how-peopleread-web-eyetracking-evidence/

31. Postman, N. (1998). Five Things We Need to Know about Technological Change. Talk delivered in Denver Colorado on March 28 , 1998.

Available: https://web.cs.ucdavis.edu/ rogaway/classes/188/materials/postman.p df

32. Prensky, M. (2001). Digital Natives, Digital Immigrants - Part 1. On the Horizon, 9(5), 1-6.

33. Prensky, M. (2001). Digital Natives, Digital Immigrants - Part 2: Do They Really Think Differently? On the Horizon, 9(6), 1-6.

34. Pros, R.C., Tarrida, A.C., Martin, M.M.B. \& Amores, M.C.C. (2013). Effects of the PowerPoint methodology on content learning. Intangible Capital, 9(1), 184-198.

35. Rello, L \& Bigham, J.P. (2017). Good Background Colors for Readers: A Study of People with and without Dyslexia. ASSETS 17. DOI: https://doi.org/10.1145/3132525.3132546

36. Rogowsky, B.A., Calhoun, B.M. \& Tallal, P. (2016). Does Modality Matter? The Effects of Reading, Listening, and Dual Modality on Comprehension. SAGE Open, July-September 2016, 1-9. Available: https://journals.sagepub.com/doi/abs/10.1177/2158244016669550

37. Salmeron, L. \& Llorens, A. (2019). Instruction of Digital Reading Strategies Based on Eye-Movements Modeling Examples. Journal of Educational Computing Research, 57(2), 343-359.

38. Schcolnik, M. (2001). A Study of Reading with Dedicated EReaders. Ph.D. dissertation. Graduate School of Computer and Information Sciences, Nova Southeastern University. Available: http://www.planetebook.com/downloads/schcolnik.pdf

39. Schcolnik, M. (2002). Are E-Readers Viable Instructional Delivery Systems? Journal of Instruction Delivery Systems, 16(4), 6-17.

40. Schcolnik, M. \& Kol, S. (June 2005). Digital Text Presentation for Learning. Proceedings of EdMedia 2005 - World Conference on Educational Multimedia, Hypermedia \& Telecommunications. Montreal, Canada. 
41. Schcolnik, M. \& Kol, S. (2006). Reading and Learning from Screen. In P. Zaphiris (Ed.) User Centered Computer Aided Language Learning. Hershey, Pennsylvania: Idea Group Publishing, 257-277.

42. Schcolnik, M. \& Feuerstein, T. (2018). Teaching Reading Comprehension Skills in ESL/EFL. Raanana, Israel: University Publishing Projects Ltd.

43. Schcolnik, M. (2018). Digital Tools in Academic Writing? Journal of Academic Writing, 8(1), 121-130.

Available: https://publications.coventry.ac.uk/index.php/joaw/article/view/360

44. Sorensen, B.M. (2015). Let's ban PowerPoint in lectures - it makes students more stupid and professors more boring. Available: https://theconversation.com/lets-ban-powerpoint-in-lectures-itmakes-students-more-stupid-and-professors-more-boring-36183

45. Wikipedia - Reading Machine. Available: en.wikipedia.org/wiki/Reading_machine

46. Wolf, M. \& Barzillai, M. (2009). The Importance of Deep Reading. Educational Leadership, 66(6), 32-37.

47. Wolf, M. (2018). Podcast: The science of reading in a digital age. Phi Delta Kappan. Available: https://kappanonline.org/podcast-sciencereading-digital-age/

48. Wood S.G., Moxley, J.H., Tighe, E.L. \& Wagner, R.K. (2018). Does Use of Text-to-Speech and Related Read-Aloud Tools Improve Reading Comprehension for Students with Reading Disabilities? A Meta-Analysis. Journal of Learning Disabilities, 51(1), 73-84. SAGE.

49. Worthington, D.L. \& Levasseur, D.G. (2015). To Provide or Not to Provide Course PowerPoint Slides? The Impact of InstructorProvided Slides upon Student Attendance and Performance. Computers \& Education 85,14-22. 